\title{
The application of multivariate analysis of variance (MANOVA) to evaluate plant metabolomic data from factorially designed experiments
}

Helen E. Johnson ${ }^{1,3}$ - Baldeep Kular ${ }^{2}$ Luis Mur ${ }^{1}$ Aileen R. Smith ${ }^{1}$. Trevor L. Wang ${ }^{2}$. David R. Causton ${ }^{1}$

(C) Springer Science+Business Media, Inc. 2005

This article has been withdrawn due to differences in interpretation of the results.

Helen E. Johnson

Helen.E.Johnson@manchester.ac.uk

1 Institute of Biological Sciences, University of Wales,

Cledwyn Building, Aberystwyth SY23 3DD, UK

2 John Innes Centre, Norwich Research Park, Colney,

Norwich NR4 7UH, UK

3 Faculty of Life Sciences, University of Manchester, 3.614

Stopford, Oxford Road, Manchester M13 9PT, UK 